đa phần là không có ý nghĩa thống kê. Ngoại trừ, sự khác biệt về thái độ cho rằng trẻ tự kỷ đều bị thiểu năng trí tuệ giữa các nhóm tuổi là có ý nghĩa $(p<0,001)$, ở nhóm <33 tuổi có thái độ đúng hơn so với nhóm >33 tuổi. Có thể do nhóm giáo viên trẻ hơn dễ dàng tiếp cận với xu hướng thay đổi nhận thức hiện đại hơn. Đều này cũng tương đồng với tác giả Đào Thị Sâm [3] nghiên cứu trên đối tượng phụ huynh. Tuy nhiên có khác biệt với tác giả Liu Y [9], nghiên cứu lại chỉ ra thái độ về tự kỷ có liên quan đến trình độ học vấn $(p<0,05)$ và thậm chí loại trường đang dạy cũng có liên quan. Điều này có thể lý giải do nghiên cứu ở hai đất nước khác nhau nên mối quan tâm về vấn đề này cũng khác nhau ở các nhóm đối tượng. Mặc dù là nhóm nào, thái độ đúng của giáo viên mầm non rất quan trọng đối với tương lai sau này của trẻ tự kỷ.

\section{KẾT LUẬN}

Kết quả nghiên cứu cho thãy, tất cả GVMN tham gia khảo sát đã từng nghe đến bệnh tự kỷ và hơn $90 \%$ có kiến thức đúng về khái niệm của RLPTK. Kiến thức của GVMN tại Cần Thơ tương đối đồng đều ở các nhóm và đạt điểm khá cao (23-26/30) trong đó hơn $90 \%$ không có kiến thức sai lầm về điều trị nhưng kiến thức đúng về dấu hiệu cờ đỏ chỉ ở mức trung bình. Kinh nghiệm chăm sóc trẻ đóng vai trò quan trọng trong việc giúp GVMN có kiến thức đúng về RLPTK. Về thái độ, GVMN tin rằng điều trị có thể giúp được cho trẻ và trẻ mắc RLPTK cần được học tại các trường/lớp chuyên biệt.

\section{TÀI LIÊU THAM KHẢO}

1. Bùi Thi Hoài Ân (2019), "Nhân thức về rối loạn phổ tư kỷ của giáo viên một số trường chuyên biệt tại thành phố Hồ Chí Minh", Đại học Sư Phạm thành phố Hồ Chí Minh.

2. Bùi Thị Thu Hà và cộng sự (2019), "Nghiên cứu kiến thức, thái độ và thực hanh cưa cha mẹ, cán bộ y tế và giáo viển mầm non về rối loạn tự kỷ ở trẻ em tại cộng đồng".

3. Đào Thị Sâm (2013), "Khảo sát thái độ của cha me đối với con có chứng tự kỷ".

4. Trần Thiện Thắng (2020), "Khảo sát tỷ lệ trẻ từ 18-36 tháng có biểu hiên Rôi loan Phổ tư kỷ tại khoa khám Bệnh viện Nhi Đồng Cần Thơ bằng thang điểm M-Chat"' Tap chí Đai hoc Y Dước Cần Thơ.

5. Vũ Văn Thuấn (2013), Thái độ của giáo viên mầm non trên địa bàn thành phố Hà Nội về tự kỷ, Luận văn Thạc sĩ Tâm lý học.

6. Humphrey $\mathbf{N}$, Symes W.(2013), "Inclusive education for pupils with autistic spectrum disorders in secondary mainstream schools: teacher attitudes, experience and knowledge", International Journal of Inclusive Education.

7. Haimour \& Yahia F. Obaidat, "School Teachers' Knowledge about Autism in Saudi Arabia Abdulhade".

8. Lian WB, Kristen Clancy Mancilla và cộng sự (2020), "Prevalence of Autism Spectrum Disorder Among Children Aged 8 Years-Autism and Developmental Disabilities Monitoring Network, 11 Sites, United States", Urveillance Summaries, 69(4), pp. 1-12.

9. Liư 'Y. và cộng sư' (2016), "Knowledge, attitudes, and perceptions of autism spectrum disorder in a stratified sampling of preschool teachers in China", BMC Psychiatry.

\title{
KHẢO SÁT VIỆC KÊ ĐO'N THUỐC ĐIỀU TRI HELICOBACTER PYLORI TẠI MộT BỆNH VIỆN THÀNH PHỐ HỒ CHÍ MINH
}

\section{TÓM TẮT}

Mở đâu: Nhiễm Helicobacter pylori (H. pylori) có thể là nguyên nhân dẫn đến nhiêu bênh lý đường tiêu hoá trên. Các phác đồ điều trị viêm loét dạ dày có $\mathrm{H}$. pylori dương tính được câp nhất với tình hình đề kháng kháng sinh của vi khuẩn. Mục tiêu: Khảo sát việc kê đơn thuốc điều trị loét dạ dày tá tràng có H.pylori dương tính tại một bệnh viện Thành phố Hồ

${ }^{1}$ Đại học Y Dược Thành phố Hồ Chí Minh 'Bệnh viên Chợ Rẫy

33ệnh viện Thống Nhất, Thành phố Hồ Chí Minh Chịu trách nhiệm chính: Võ Duy Thông

Email: duythong@ump.edu.vn

Ngày nhận bài: 18.2.2021

Ngày phản biện khoa họ: 29.3.2021

Ngày duyệt bài: 6.4 .2021
Võ Duy Thông ${ }^{1,2}$, Nguyễn Thanh Hải ${ }^{3}$

Chí Minh. Đối tượng và phương pháp: Nghiên cứu cắt ngang mô tả trên đơn thuốc của bệnh nhân ngoại trú có chẩn đoán loét da dày tá tràng có H.pylori dương tính, được trong tháng 3 năm 2021. Các đơn thuốc được đưa vào nghiên cứu là đơn thuốc có đây đủ thông tin của bênh nhân, thông tin phòng khám và thông tin thuốc điêuu trị. Tính hợp lý trong kê đơn được được đánh giá thồng qua phác đồ điều trị của Đồng thuận ASEAN 2016 và Đồng thuận Maastricht V/ Florence 2016. Kết quả: Có 96 đơn thuốc ngoại trú đước đưa vào nghiên cứu, tuổi trung bình của bệnh nhẩn là 48 tuổi, $59,4 \%$ là nữ. Phác đồ 4 thuốc có bismuth là phác đồ phổ biến nhất được sử dụng $(77,1 \%)$. Tỷ lệ đơn thuốc có ít nhất 1 vấn đề chưa hợp lý là $29,2 \%$. Những vấn đề chưa hợp lý thường gặp bao gồm sử dụng chưa hợp lý liều bismuth, liều metronidazol/tinidazol và liều thuốc ức chế bơm proton (PPI). Bác sĩ ngoại khoa có tỷ lệ kê đơn chưa 
hợp lý cao hơn có ý nghĩa thống kê so với bác sĩ nội khoa $(37,9 \%$ so với $15,8 \%, p=0,023)$. Kết luân: Việc kê đơn thuốc điều trị $H$. pylori chưa hợp lý cò̀n tương đối cao. Cần cập nhật liên tục các hướng dẫn điều trị $\mathrm{H}$. pylori thường xuyên giúp các bác sĩ kê đơn thuốc hợp lý, từ đó nâng cao hiệu quả điều trị cho bệnh nhần.

Tư khoá: đơn thuốc, vấn đề chưa hợp lý, bệnh nhân ngoại trú.

\section{SUMMARY}

\section{INVESTIGATION ON THE PRESCIPTIONS} FOR PATIENTS WITH HELICOBACTER PYLORI AT A HOSPITAL IN HO CHI MINH CITY

Background: Helicobacter pylori (H. pylori) infection is the main cause of several upper gastrointestinal diseases. Tretment guidelines for $\mathrm{H}$. pylori has been updated base on the antimicrobial resistance of $\mathrm{H}$. pylori. Objective: Evaluate the appropriateness of drug use in prescriptions of patienst with $\mathrm{H}$. pylori at a Hospital, Ho Chi Minh City. Materials and Methods: A cross - sectional study was conducted on prescriptions of outpatients diagnosed with $\mathrm{H}$. pylori, in March 2021. Prescriptions were reviewed for data analysis including all information of patients, clinics and drug used. The appropriateness of precriptions was accessed based on the 2016 Maastricht V/Florence Consensus and the 2016 ASEAN Consensus. Results: There were 96 priscriptions of outpatients included in this study. The mean age of patients was 48 y.o, 59.4\% was female. Bismuth quadruple therapy was the most commonly prescribed in patients $(77.1 \%)$. The rate of prescriptions with at least one error was $29.2 \%$. The common prescribing errors were inpropriateness in bismuth, metronidazole/tinidazole, and PPI dosage. The surgeons made a higher rate of prescribing errors than internal doctors.

Keywords: prescription, medication error, outpatient.

\section{I. ĐẶT VẤN ĐỀ}

Nhiễm Helicobacter pylori (H. pylori) là bênh nhiễm khuẩn dẫn tới các bệnh lý đường tiêu hoá trên như viêm dạ dày mạn tính, loét dạ dạy tá tràng, ung thư dạ dày. Theo một nghiên cứu tổng quan hệ, tổng kết nghiên cứu năm 20132014 cho thấy tỷ lệ nhiễm H. pylori cao nhất là ở khu vực Châu Á, Đông Âu và Nam Phi (trên $50 \%$ ) [1]. Việc sử dụng thuốc hợp lý trong tiệt trừ $\mathrm{H}$. pylori đóng vai trò rất quan trọng nhằm giảm thiểu các biến chứng nguy hiểm của bệnh trên bệnh nhân. Do đó, cần lựa chọn thuốc phù hợp theo các khuyến cáo, đặc biệt là sử dụng hợp lý thuốc kháng sinh, cập nhật theo tình hình đề kháng kháng sinh tại địa phương. Điều này giúp tối ưu hoá hiệu quả tiệt trừ $\mathrm{H}$. pylori. Tại Việt Nam, Điều trị $\mathrm{H}$. pylori được đề cập trong Phác đồ điều trị của Hội tiêu hoá Việt Nam năm 2013 và Hướng dẫn sử dụng kháng sinh của Bộ Y tế năm năm 2015. Tuy nhiên, những phác đồ này có điểm chưa thực sự cập nhật theo khuyến cáo của khu vực và thế giới trong những năm gần đây, nhất là theo tình hình đề kháng kháng sinh của vi khuẩn gây bệnh. Do đó, trong nghiên cứu này chúng tôi sử dụng phác đồ điều trị cập nhật hơn, dựa trên tình hình đề kháng của $H$. pylori tại khu vực ASEAN (Đồng thuận ASEAN 2016 [2]) và Châu Á Thái Bình Dương (Đồng thuânn Maastricht V 2016 [3]). Nghiên cứu được tiên hành với mục tiêu khảo sát việc sử dụng các phác đồ điều trị $\mathrm{H}$. pylori và nhận xét về tính hợp lý trong việc kê đơn thuốc điêu trị H. pylori.

\section{II. ĐỐI TƯỢNG VÀ PHƯƠNG PHÁP NGHIÊN CỨU}

Thiết kế nghiên cứu. Nghiên cứu cắt ngang mô tả trên đơn thuốc của bệnh nhân ngoại trú có chẩn đoán viêm loét dạ dày tá tràng có $\mathrm{H}$. pylori dương tính, tới khám và điều trị ngoại trú tại Khoa Khám bệnh, bệnh viện nghiên cứu trong tháng 3 năm 2021.

\section{Tiêu chuẩn chọn mẫu}

- Đơn thuốc của bênh nhân có chẩn đoán viêm loét da dày tá tràng có $\mathrm{H}$. pylori dương tính

- Đơn thuốc đầy đủ thông tin của bệnh nhân, bao gồm: mã số bệnh nhân, tên, tuổi, giới tính, chẩn đoán.

\section{Có đầy đủ thông tin phòng khám}

- Có đầy đủ thông tin thuốc điều trị (tên thuốc, dạng bào chế, đường dùng, liều dùng, tần suất dùng, thời gian dùng thuốc)

Các định nghĩa trong nghiên cứu: Kê đơn thuốc điều trị $\mathrm{H}$. pylori được cho là hợp lý nếu thoả mãn tất cả tiêu chí về chỉ định phối hợp thuốc, liêu dùng, tần suất dùng thuốc, thời gian điêu trị tuân thủ theo 1 trong 2 khuyến cáo của Đồng thuận ASEAN 2016 [2] hoặc Maastricht V 2016 [2]. Bảng 1 trình bày tổng hợp các phối hợp thuốc phố biến được khuyến cáo theo các Đồng thuận tham khảo.

Bảng 1. Tổng hợp phác đồ được sử dụng tại bệh viên [2], [3]

\begin{tabular}{|c|c|c|c|}
\hline Tên phác đồ & \multicolumn{1}{|c|}{ Thuốc phối hợp, hàm lượng } & \multicolumn{1}{c|}{ Tân suất dùng } & $\begin{array}{c}\text { Thời gian } \\
\text { dùng }\end{array}$ \\
\hline 4 thuốc có Bismuth & $\begin{array}{l}\text { ismuth subsalicylate } 120-300 \mathrm{mg} \text { hoặc } \\
\text { bismuth subcitrate } 300-420 \mathrm{mg} \\
\text { Tetracycline } 500 \mathrm{mg}\end{array}$ & $\begin{array}{c}\text { 4ần/ngày (cùng các bữa ăn } \\
\text { và trước khi đi ngư) } \\
\text { 4lân/ngày (cùng các bữa ăn }\end{array}$ & 14 ngày \\
\hline
\end{tabular}




\begin{tabular}{|c|c|c|c|}
\hline & $\begin{array}{l}\text { Metronidazole } 500 \mathrm{mg} / \text { tinidazole } 500 \mathrm{mg} \\
\text { PPI }\end{array}$ & $\begin{array}{c}\text { và trước khi đi ngủ) } \\
3-4 \text { lần/ngày } \\
2 \text { lần/ngày } \\
\end{array}$ & \\
\hline $\begin{array}{l}4 \text { thuốc có Bismuth } \\
\text { (thay thế tetracyclin } \\
\text { bằng amoxicillin) }\end{array}$ & $\begin{array}{l}\text { Bismuth subsalicylate hoặc bismuth } \\
\text { subcitrate } \\
\text { Amoxicillin } 1 \mathrm{~g} \\
\text { Metronidazole } 500 \mathrm{mg} / \text { tinidazole } 500 \mathrm{mg} \\
\text { PPI }\end{array}$ & $\begin{array}{c}4 \text { lần/ngày (cùng các bữa ăn } \\
\text { và trước khi đi ngư) } \\
2 \text { lần/ngày } \\
3 \text { lần/ngày } \\
2 \text { lần/ngày }\end{array}$ & 14 ngày \\
\hline $\begin{array}{c}4 \text { thuốc không có } \\
\text { Bismuth }\end{array}$ & $\begin{array}{l}\text { Amoxicillin } 1 \mathrm{~g} \\
\text { Clarithromycin } 500 \mathrm{mg} \\
\text { Tinidazole } 500 \mathrm{mg} / \mathrm{metronidazol} 500 \mathrm{mg} \\
\text { PPI }\end{array}$ & $\begin{array}{l}2 \text { lần/ngày } \\
2 \text { lần/ngày } \\
2 \text { lần/ngày } \\
2 \text { lần/ngày } \\
\end{array}$ & 14 ngày \\
\hline $\begin{array}{c}3 \text { thuốc truyên thống } \\
\text { (khi tỳ lệ kháng } \\
\text { clarithromycin < } \\
15 \%)\end{array}$ & $\begin{array}{l}\text { Amoxicillin 1g VÁ } 1 \text { trong các thuốc sau: } \\
\text { clarithromycin } 500 \text { mg hoăc tinidazole } \\
(500 \mathrm{mg}) \text { hoặc metronidazole } 500 \mathrm{mg} \\
\text { PPI }\end{array}$ & $\begin{array}{l}2 \text { lần/ngày } \\
2 \text { lần/ngày } \\
2 \text { lần/ngày }\end{array}$ & 14 ngày \\
\hline $\begin{array}{l}3 \text { thuốc có } \\
\text { levofloxacin }\end{array}$ & $\begin{array}{l}\text { Levofloxacin } 500 \mathrm{mg} \\
\text { Amoxicillin } 1 \mathrm{~g} \\
\text { PPI }\end{array}$ & $\begin{array}{l}1 \text { lần/ngày } \\
2 \text { lần/ngày } \\
2 \text { lần/ngày }\end{array}$ & 14 ngày \\
\hline
\end{tabular}

Cõ̃ mẫu: Lựa chọn tất cả các đơn thuốc thỏa tiêu chuẩn chọn mấu

\section{Các thông số khảo sát}

Khảo sát đặc điểm của mẫu nghiên cứu:

- Đặc điểm liên quan đến bệnh nhân: Tuổi, giới tính

- Đặc điểm liên quan đến bác sĩ: Giới tính, trình độ chuyên môn, chuyên ngành, phòng khám

Khảo sát phác đồ điều trị H.pylori và nhận xét tính hợp lý: Loại phác đồ điều trị, các vấn đề chưa hợp lý trong đơn, tính hợp lý chung.

Phân tích số liệu. Phần mềm thống kê sử dụng: Excel 2010 và SPSS 20.0. Biến liên tục thỏa mãn kiểm định tham số (phân phối chuẩn và phương sai đồng nhất) được trình bày bằng giá trị trung bình \pm độ lệch chuẩn. Biến liên tục không thỏa mãn kiểm định tham số (không phẩn phối chuẩn và/ hoặc phương sai không đồng nhất) được trình bày bằng số trung vị (khoảng tứ phân vị - IQR 1, IQR 3). Các biến phân loại được trình bày bằng tỷ lệ phần trăm. So sánh tỷ lệ đơn thuốc có ít nhất 1 vấn đề chưa hợp lý giữa các nhóm giới tính, trình độ bác sĩ, chuyên ngành của bác sĩ - sử dụng phép kiểm chi bình phương. Khác biệt được coi là có ý nghĩa thống kê khi $\mathrm{p}<0,05$.

Vấn đề y đức: Đề tài đã được thông qua Hội đồng $Y$ đức Bệnh viện nghiên cứu.

\section{KẾT QUẢ NGHIÊN CỨU}

Đặc điểm chung của mẫu nghiên cứu. Trong thời gian nghiên cứu, chúng tôi lựa chon được 96 đơn thuốc của bệnh nhân thoả mãn tiều chuẩn chọn mẫu. Các đặc điểm liên quan đến bệnh nhân và bác sĩ trên đơn.
Bảng 2. Đăc tính mẫu nghiên cứu $(n=96)$

\begin{tabular}{|c|c|}
\hline Đắc điếm & Giá trị \\
\hline \multicolumn{2}{|c|}{ Đăc điếm liên quan đến bênh nhân } \\
\hline Tuối, TB $\pm \mathrm{SD}^{*}$ & $48 \pm 13$ \\
\hline \multicolumn{2}{|l|}{ Giới, n (\%) } \\
\hline Nam & $39(40,6 \%)$ \\
\hline Nữ & $57(59,4 \%)$ \\
\hline \multicolumn{2}{|c|}{ Đặc điếm liên quan đến bác sĩ } \\
\hline \multicolumn{2}{|c|}{\begin{tabular}{|l|l} 
Giới tính của bác sĩ &
\end{tabular}} \\
\hline Nam & $76(79,2 \%)$ \\
\hline Nũ̃ & $20(20,8 \%)$ \\
\hline \multicolumn{2}{|l|}{ Trình độ chuyên môn } \\
\hline Bác sĩ & $43(44,8 \%)$ \\
\hline Thac sĩ - chuyên khoa 1 & $30(31,3 \%)$ \\
\hline Tiến sĩ - chuyên khoa 2 & $23(24 \%)$ \\
\hline \multicolumn{2}{|c|}{ Chuyên ngành của bác sĩ } \\
\hline Nội & $38(39,6 \%)$ \\
\hline Nôi tiêu hoá & $11(11,5 \%)$ \\
\hline Nội tống quát & $24(25,0 \%)$ \\
\hline Khác & $3(3,1 \%)$ \\
\hline Ngoại & $58(60,4 \%)$ \\
\hline Ngoai tiều hoá & $56(58,3 \%)$ \\
\hline Ngoại ngan mật tuy. & $2(2,1 \%)$ \\
\hline \multicolumn{2}{|l|}{ Phòng khám } \\
\hline Nội tiêu hoá & $10(10,4 \%)$ \\
\hline Ngoại tiêu hoá & $56(58,3 \%)$ \\
\hline Nồi chung & $24(25 \%)$ \\
\hline Khác & $6(6,3 \%)$ \\
\hline
\end{tabular}

*TB \pm SD: trung bình \pm độ lệch chuấn

Khảo sát phác đồ điêu trị H.pylori và nhận xét tính hợp lý. Trong nghiên cứu này, đa số bệnh nhân được chỉ định phác đồ 4 thuốc có bismuth (77,1\%). Số ngày điều trị trung bình của bệnh nhân là 10 ngày (Bảng 3 ).

Bảng 3. Phác đồ điều trị H.pylori $(n=96)$ 


\begin{tabular}{|c|c|c|}
\hline \multicolumn{2}{|l|}{ Tên phác đồ } & $\begin{array}{l}\text { Số lượng } \\
\text { (Tỷ lệ \%) }\end{array}$ \\
\hline \multicolumn{2}{|c|}{ Phác đồ 4 thuốc có bismuth } & $74(77,1 \%)$ \\
\hline \multicolumn{2}{|c|}{ Phác đồ cứu vãn có levofloxacin } & $10(10,4 \%)$ \\
\hline \multicolumn{2}{|c|}{ Phác đồ truyền thống 3 thuốc OAC } & $9(9,4 \%)$ \\
\hline \multicolumn{2}{|c|}{ Phác đồ 4 thuốc không có Bismuth } & $3(3,1 \%)$ \\
\hline Số ngày điều trị, TB \pm & SD* & $10 \pm 3,4$ \\
\hline \multicolumn{3}{|c|}{$\begin{array}{l}\text { Tỷ lệ đơn thuốc có ít nhất } 1 \text { vấn đề chưa hợp } \\
\text { lý trong kê đơn là } 29,2 \% \text {. Các vấn đề liên quan } \\
\text { đến kê đơn khác được trình bày trong bảng } 4 \text {, } \\
\text { bảng } 5 . \\
\text { Bảng 4. Tính hợp lý của việc kê đơn thuốc } \\
\text { điều trị H.pylori }(n=96)\end{array}$} \\
\hline Tính hợp lý & \multirow{2}{*}{\multicolumn{2}{|c|}{ Số lượng (Tỷ lệ \%) }} \\
\hline Hợp lý & & \\
\hline $\begin{array}{c}\text { Chưa hợp lý (có ít nhất } 1 \\
\text { vấn đề chưa hợp lý) }\end{array}$ & \\
\hline 1 vấn đề & \multicolumn{2}{|c|}{$22(22,9 \%)$} \\
\hline 2 vấn đề & \multicolumn{2}{|c|}{$6(6,3 \%)$} \\
\hline $\begin{array}{l}\text { Trung bình vấn đề chưa } \\
\text { hợp lý/đơnn }\end{array}$ & \multicolumn{2}{|c|}{$0,35 \pm 0,59$} \\
\hline
\end{tabular}

Bảng 5. Thống kê các loại vấn đề chưa hợp lý trong kê đơn điều trị H. pylori $(n=28)$

\section{Các trường hợp chưa hợp lý}

Liều bismuth chưa hợp lý, $\mathrm{n}(\%) \quad 17(60,7 \%)$

Liều metronidazol/ tinidazol chưa hợp lý, n (\%)

Liều amoxicillin chưa hợp lý, n (\%) 1 1 (3,6\%)

Liều PPI chưa hợp lý, n (\%) $2(7,1 \%)$

Liều tetracyclin chưa hợp lý, n (\%) $5(17,9 \%)$

*Có đơn thuốc có nhiều hơn 1 vấn đề chưa hợp lý nên tổng tỷ lệ không bằng $100 \%$

Kết quả phân tích một số các yếu tố có liên quan tới vấn đề chưa hợp lý trong phân tích đơn biến cho thấy, bác sĩ chuyên ngành ngoại khoa có tỷ lệ kê đớn có vấn đề chưa hợp lý cao hơn có ý nghĩa thống kê so với bác sĩ nội khoa. Tất cả các bác sĩ chuyên ngành nội tiêu hoá trong nghiên cứu đều kê đơn hợp lý theo khuyến cáo (bảng 5).

Bảng 5. Các yếu tố có liên quan đến vấn đề chưa hợp lý trong kê đơn

\begin{tabular}{|c|c|c|}
\hline Đặc điểm & $\begin{array}{l}\text { Vấn đề chưa } \\
\text { hợp lý, n(\%) }\end{array}$ & $\mathbf{p}$ \\
\hline \multicolumn{3}{|c|}{ Giới tính của bác sĩ } \\
\hline Nũ $(n=20)$ & $3(15 \%)$ & \multirow{2}{*}{0,117} \\
\hline $\operatorname{Nam}(n=76)$ & $25(32,9 \%)$ & \\
\hline \multicolumn{3}{|c|}{ Trình độ của bác sĩ } \\
\hline Bác sĩ $(n=43)$ & $11(25,6 \%)$ & \multirow{3}{*}{0,094} \\
\hline $\begin{array}{l}\text { Thạc sĩ - chuyến } \\
\text { khoa } 1(\mathrm{n}=30)\end{array}$ & $13(43,3 \%)$ & \\
\hline Tiến sĩ - chuyên & $4(17,4 \%)$ & \\
\hline
\end{tabular}

\begin{tabular}{|c|c|c|}
\hline khoa 2 $(\mathrm{n}=23)$ & & \\
\hline \multicolumn{3}{|c|}{ Chuyên ngành của bác sĩ } \\
\hline Nội $(\mathrm{n}=38)^{*}$ & $6(15,8 \%)$ & $\mathbf{0}$ \\
\hline Ngoại $(\mathrm{n}=58)$ & $22(37,9 \%)$ & \\
\hline
\end{tabular}

Trong đó: Tỷ lệ vấn đề chưa hợp lý của bác sĩ chuyên ngành nội tiêu hoá là $0 \%$

\section{BÀN LUÂ̂N}

Tuổi trung bình của bệnh nhân nhiễm $\mathrm{H}$. Pylori trong nghiên cứu là $48 \pm 13$ tuổi. H. pylori là vi khuẩn có thể mắc ở mọi lứa tuổi. Nghiên cứu của Pounder RE và cộng sự cho thấy, hơn $50 \%$ dân số thế giới bị nhiếm H. pylori. Nhiễm khuẩn này thường xảy ra ở trẻ em, thanh thiếu nhiên ở các nước phát triển [4]. Tuy nhiên, thường gặp ở cả những độ tuối lớn hơn ở các nước đang phát triển. Nghiền cứu của chúng tôi có kết quả tương tự về độ tuổi so với nghiên cứu thực hiên tại Mexico khi đa số bệnh nhân người lớn nhiễm H. pylori là ở độ tuổi trung niên [5].

Trong một nghiên cứu trên 13 chủng H. pylori tại thành phố Hồ Chí Minh và Hà Nội năm 2008, tỷ lệ vi khuẩn đề kháng với các kháng sinh cao báo động. Cụ thể, tỷ lệ đề kháng của $\mathrm{H}$. pylori với clarithromycin là 23,5-33\%, lớn hơn $15 \%$ Do đó phác đồ 3 thuốc OAC truyền thống dường như không còn phù hợp là lựa chọn đầu tay trong điêu trị cho bệnh nhân tại khu vực TP. Hồ Chí Minh [6]. Trong nghiên cứu của chúng tôi, phác đồ được sử dụng nhiều nhất là phác đồ 4 thuốc có bismuth $(77,1 \%)$, trong khi các phác đồ 4 thuốc không bismuth, 3 cứu vãn với levofloxacin, 3 thuốc truyền thống ít được dùng (tỷ lệ $3,1 \% ; 9,4 \% ; 10,4 \%$ tương ứng). Điều này phù hợp, do ở các nước Châu Á gần đây hiệu quả của các phác đồ 3 thuốc đang giảm. Theo nghiên cứu của Yoshio Yamaoka và cộng sự (2015) [7], tình hình đề kháng của H. pylori với các kháng sinh dùng trong phác đồ tiệt trừ gia tăng theo nghiên cứu của Reza Malekzadeh và cộng sự (2014) [8], nghiên cứu của Miyoung Choi (2021)[9]. Việc thêm Bismuth vào phác đồ điều trị làm gia tăng tỷ lệ thành công theo nghiên cứu của Hong Lu và cộng sự (2018).

Phác đồ 4 thuốc có Bismuth dùng trong 14 ngày là phác đồ được chứng minh có hiệu quả tiệt trừ $\mathrm{H}$. pylori vượt trội so với phác đồ 3 thuốc truyền thống $\mathrm{OAC}$. Nghiên cứu tổng quan hệ thống năm 2013 tổng hợp lết quả của 12 nghiên cứu thử nghiệm lâm sàng ngẫu nhiên có nhóm chứng thực hiện tại Châu Á, Châu Âu và Bắc Mỹ so sánh hiệu quả tiệt trừ $H$. pylori của phác đồ 4 thuốc có bismuth và phác đồ OAC cho thấy tỷ lệ tiệt trừ thành công tương ứng là $78 \%$ so với $69 \%$. 
Trong nghiên cứu tổng quan hệ thống so sánh hiệu quả tiệt trừ $\mathrm{H}$. pylorri của phác đồ 3 thuốc có levofloxacin và phác đồ $\mathrm{OAC}$ truyền thống, sử dung trong 10-14 ngày cho thấy hiêu quả tiệt trừ H.pylori vượt trội (90\% so với $73 \%)$ của phác đồ có levofloxacin. Việc sử dụng thêm thuốc Bismuth trong phác đồ 3 thuốc có levofloxacin giúp gia tăng hiệu quả tiệt trừ vi khuẩn.

Tỷ lệ đơn thuốc chưa hợp lý chiếm 29,2\%, chủ yếu là một vấn đề chưa hợp lý $(22,9 \%)$. Sứ dụng liều dùng các thuốc chưa hợp lý là những vấn đề phổ biến, đặc biệt là với liều dùng của bismuth $(60,7 \%)$. Tổng số lỗi ghi nhận được trong nghiên cứu của Sayers YM và cộng sự là 672 lỗi trong số 491 đơn thuốc. Tỷ lê các loại sai sót có sự khác biệt rõ rệt giữa các nghiên cứu. Nghiên cứu của tác giả Anthony J Avery và cộng sự cho thấy tỷ lệ sai sót cao hơn là $4,1 \%$ (247/6048; $95 \%$ CI $=3.6 \%-4.6 \%)$, trong đó sai sót về không đầy đủ thông tin trong đơn thuốc chiếm tỷ lệ cao nhất. Các sai sót về chỉ định được chia ra cụ thể (sai thuốc, chống chỉ định,...) trong nghiên cứu của Avery AJ. và cộng sự, nhưng nhìn chung tỷ lệ này thấp hơn so với tỳ lệ thu được trong nghiên cứu của chúng tôi.

Các bác sĩ ngoại khoa có xu hướng kê đơn thuốc điều trị $\mathrm{H}$. pylori chưa hợp lý cao hơn so với các sĩ nội khoa. Điều này có thể giải thích do thực tế việc điều trị $H$. pylori là liệu pháp điều trị nôi khoa, các bác sĩ nội được câp nhât thông tin điều trị nội khoa thường xuyên hơn. Do đó, cần triển khai các buổi đào tao liên tự về các vấn đề điều trị nội khoa cho các bác sĩ giúp nâng cao tính hợp lý trong kê đơn thuốc.

\section{KẾT LUÂ̂N}

Việc kê đơn thuốc điều tri $H$. pylori chưa hợp lý còn tương đối cao. Cần cập nhật liên tục các hướng dẫn điều trị $\mathrm{H}$. pylori thường xuyên giúp các bác sĩ kê đơn thuốc hợp lý, từ đó nâng cao hiệu quả điều trị cho bệnh nhân.

\section{TÀI LIỆU THAM KHẢO}

1. Eusebi L. H. et al. (2014), "Epidemiology of Helicobacter pylori infection". Helicobacter, 19(1), pp.1-5.

2. Varocha M. et al. (2018), "Helicobacter pylori management in ASEAN: The Bangkok consensus report". Journal of Gastroenterology and Hepatology, 33, pp. 37-56.

3. Malfertheiner $P$, et al. (2017), "Management of Helicobacter pylori infection-the Maastricht V/Florence Consensus Report". Gut, 66, pp.6-30.

4. Pounder RE et al. (1995), "The prevalence of Helicobacter pylori infection in different countries". Aliment Pharmacol Ther, 9(2), pp. 33.

5. Torres J, et al. (1998), "A community-based seroepidemiologic study of Helicobacter pylori infection in Mexico". J Infect Dis, 178, pp. 1089.

6. Binh TT, et al. (2012), "The incidence of primary antibiotic resistance of Helicobacter pylori in Vietnam". J Clin Gastroenterol, 47(3), pp. 233-238.

7. Yamaoka Y, et al. (2015), "Appropriate first-line regimens to combat Helicobacter pylori antibiotic resistance: an Asian perspective". Molecules (Basel, Switzerland), 20(4), pp. 6068-6092.

8. Malekzadeh R, et al. (2014), "Helicobacter pylori eradication in West Asia: a review". World journal of gastroenterology, 20(30), pp. 10355-10367.

9. Choi M, et al. (2021), "Korean College of Helicobacter and Upper Gastrointestinal Research. Evidence-Based Guidelines for the Treatment of Helicobacter pylori Infection in Korea 2020". Gut Liver, 15(2), pp. 168-195.

\title{
THƯ⿱C TRANG SỨC KHỎE TINH THẦn CỦA NHÂN VIÊN Y TẾ THAM GIA CÔNG TÁC PHÒNG CHỐNG DİCH BỂNH VIÊM ĐƯờNG Hô HẤP CẤP (COVID-19) Ở' MộT Số BỆNH VIÊ̂N TẠI HÀ NộI NĂM 2020
}

\author{
Bùi Thị Thanh Vân' ${ }^{1}$, Nguyễn Thị Bích Ngọc ${ }^{\text {, }}$ \\ Trần Nguyễn Ngọc $^{2}$, Đào Đức Thao ${ }^{2}$, Nguyễn Hoàng Thanh ${ }^{2}$ \\ TÓM TẮT \\ Năm 2020 đánh dấu sư xuất hiên của đai dich \\ COVID-19 trên toàn thế giới, đại dịch đã ảnh hưởng \\ lớn đến tâm lý của tất cá mọi người, đặc biệt là các \\ ${ }^{1}$ Bệnh viện Trung ương Quân đội 108 \\ 2 Trường Đại hoc Y Hà Nối \\ Chịu trách nhiếm chính: Bùi Thị Thanh Vân \\ Email: btvan118@gmail.com \\ Ngày nhận bài: 23.2.2021 \\ Ngày phản biên khoa hoc: 26.3 .2021 \\ Ngày duyệt bài: 7.4.2021 \\ nhân viên y tế ở tuyến đầu chống dịch. Mục tiêu của \\ nghiên cứu là xác định tỷ lệ lo âu, stress và trâm cảm \\ và các yếu tố liên quan đển tỷ lệ lo âu, stress, trâm \\ cảm của NVYT tham gia phòng/ chống dịch bênh \\ COVID-19. Nghiên cứu mô tả cắt ngang trên 87 NVYT \\ từ tháng 3 - tháng 6/ năm 2020.Kết quả cho thâytỷ lê \\ nhân viên y tế tham gia phòng chống dịch COVID-19 \\ tai một số bênh viên tham gia nghiên cứu có biểu hiên \\ lo âu, stress và trầm cảm lần lượt là $19,5 \%, 8 \%$ và \\ $5,7 \%$. Tỷ lê stress, lo âu, trầm cảm có liên quan đến: \\ thời gian tham gia phòng/chống dịch $(p<0,05)$, tình \\ trang hôn nhân và nghề nghiệp. Nghiên cứu giúp các \\ nhà quản lý có các chính sách để cải thiện, nâng cao
}

